\title{
Commentaries
}

\section{'Treatment-resistant' type 2 diabetes: Which definition for clinical practice?}

\section{A R T I C L E I N F O}

\section{Keywords:}

Challenge

Resistance

Therapy

Type 2 diabetes

Despite being a common feature in clinical practice and a major challenge for healthcare providers involved in the management of Type 2 Diabetes (T2D) [1], the notion of 'treatment-resistant diabetes' is scarcely found in the diabetes literature, which is instead dominated by the classic term 'insulin resistance' [2,3]. In contrast, 'treatment-resistant hypertension' is a well-known concept in the field of arterial hypertension [4]. Resistant hypertension is defined as the persistence of systolic blood pressure $\geq 160 \mathrm{mmHg}$ (or $\geq 150 \mathrm{mmHg}$ in T2D) despite pharmacological treatment with at least three antihypertensive drugs (one of which is a thiazide or loop diuretic) [5]. Based on this definition, a practical approach for managing resistant hypertension has been recommended [6], and the results of large-scale prospective clinical trials, such as the Antihypertensive and Lipid-Lowering Treatment to Prevent Heart Attack Trial (ALLHAT), have recently been re-analyzed according to this idea [7]. Yet, there is no such precise definition for 'treatment-resistant T2D', despite the fact that T2D and hypertension are two diseases that share several characteristics [8]. Mimicking the definition used for arterial hypertension, it has recently been proposed that the term 'treatment-resistant T2D' be used to refer to patients with Persistent Poorly-controlled Diabetes Mellitus (PPDM) despite standard care with three oral glucose-lowering medications [9].

Even though a global approach is recommended for the management of T2D [10], the notion of PPDM is restricted to the control of hyperglycaemia, as evaluated by the level of glycated haemoglobin $\left(\mathrm{HbA}_{1 \mathrm{c}}\right)$, which is associated with diabetic complications and considered a key marker of glycaemic control in diabetes [10-12]. Yet, this surrogate marker remains a matter of controversy [13]. As previously discussed [9], different target $\mathrm{HbA}_{1 \mathrm{c}}$ values have been proposed in the literature to define PPDM, including $>8.0 \%(64 \mathrm{mmol} / \mathrm{mol})[14,15], \geq 9.0 \%(75 \mathrm{mmol} / \mathrm{mol})$ [16] and even $\geq 10 \%$ ( $86 \mathrm{mmol} / \mathrm{mol})$ [17]. In real-life practice, however, there are numerous arguments in favour of a patientcentered approach and individualized $\mathrm{HbA}_{1 \mathrm{c}}$ targets according to the patient's profile [10-12].
The definition of standard care in T2D, restricted to the control of hyperglycaemia, is also challenging, especially given the commercialization of an increasing number of pharmacological classes, leading to a wide variety of different combination therapies [10-12]. Because of the progressive failure of beta cells, $\mathrm{T} 2 \mathrm{D}$ is an evolving disease that requires progressive treatment intensification over time to maintain adequate glucose control [10-12]. To define this topic and to keep it analogous to the definition of resistant hypertension [5], it is here proposed to define treatment-resistant diabetes as PPDM despite triple oral therapy, and before the stage of glucose-lowering injectables (insulin and Glucagon-Like Peptide [GLP]-1 receptor agonists) [9].

It was also decided to select, as triple therapy, a dual background combination of metformin plus a sulphonylurea (SU) plus another oral glucose-lowering agent (whether glitazone, dipeptidyl peptidase-4 inhibitors, sodium-glucose cotransporter type 2 inhibitors). Metformin appears to be unavoidable as it is the first-line pharmacological treatment recommended in all guidelines [10-12]. However, the choice of SU may be challenged because of the controversy concerning this class of drugs over the past five decades [18], such that a recommendation of 'use with caution' has recently been proposed [12]. Based on its efficacy (poor durability of glucose control), safety (risk of hypoglycaemia), weight control (risk of weight gain) and cardiovascular controversy [18], other pharmacological alternatives may be more advantageous. However, the latter are more expansive, recommended only as third-line therapy in some countries and not available or reimbursed in many countries.

SUs, because of their low cost and wide clinical use, have kept their place as the second-line therapy in several T2D management algorithms, including those of the American Diabetes Association (ADA)-European Association for the Study of Diabetes (EASD) position statement (2015) [11], the International Diabetes Federation (IDF, 2012) [19], the UK National Institute for Health and Care Excellence (NICE, 2016) [20] and the Haute Autorité de Santé (HAS; National Health Authority) in France (2013) [21]. This means that even if cautious use is recommended for SUs [12], these agents remain largely prescribed in combination with metformin worldwide. In terms of glucose-lowering efficacy, SUs offer at least the same efficacy as other oral antidiabetic agents, although this may diminish or disappear over time [22].

Finally, in the diabetes literature, numerous trials have tested the addition of a third oral glucose-lowering agent to the metformin plus SU dual background therapy [23]. This is also the case when the addition of an injectable glucose-lowering agent, whether insulin or a GLP-1 receptor agonist, is considered to 
improve glucose control in patients with PPDM despite oral antidiabetic therapy [24].

All these arguments support the definition proposed for treatment-resistant diabetes and the inclusion of SU in addition to metformin as background therapy [9]. As stated in the 2015 ADA-EASD position statement: "In certain patients, glucose control remains poor despite the use of three antihyperglycaemic drugs in combination. In any patient not achieving an agreed $\mathrm{HbA}_{1 \mathrm{c}}$ target despite intensive therapy, basal insulin should be considered an essential component of the treatment strategy." [11].

It is also of interest to compare treatment-resistant diabetes with so-called 'Psychological Insulin Resistance' (PIR). Although the concept is clearly different, some connections may be seen between the two. PIR refers to the reluctance of healthcare providers to prescribe, and for patients to take, insulin despite insulin therapy becoming necessary because of PPDM with oral antidiabetic therapy $[25,26]$. The Barriers to Insulin Treatment Questionnaire seems to be a reliable and valid measure of PIR in patients with T2D [27], and patient PIR can result from a range of personal viewpoints involving cognitive appraisal and/or emotional reactions [28]. More broadly, this patient perspective may manifest as a lack of compliance or adherence to glucose-lowering medications, a common finding in T2D care that can clearly contribute to PPDM $[29,30]$. As discussed in our previous article on treatment-resistant diabetes [9], poor compliance/adherence to prescribed antidiabetic therapy should always be suspected in patients with PPDM despite standard care, given that it is such a common phenomenon in T2D [29,30]. It is therefore mandatory to also take into account patient preferences when prescribing antidiabetic agents, and to facilitate communication between physicians and T2D patients to promote shared decision-making [31,32].

Patient reluctance or poor medication adherence may lead to physician clinical inertia in the management of glycaemia in T2D patients [32-34]. This may then contribute to a delay of treatment intensification and, in particular, a shift to injectable therapies (especially insulin), thereby aggravating PPDM [35,36]. Moreover, healthcare professionals face many potential barriers to insulin initiation and intensification in primary care. These can be categorized as low motivation (questions concerning efficacy), lack of familiarity with insulin (inadequate experience) and time constraints [37]. Overall, physician-, patient- and healthcaredelivery-system-related factors can all contribute to clinical inertia and PPDM [32].

Furthermore, besides poor patient adherence and physician clinical inertia, disease-specific factors may also contribute to PPDM in T2D, especially when the defect of insulin secretion cannot overcome insulin resistance. Real-life observations have revealed that achieving $\mathrm{HbA}_{1 \mathrm{c}}$ targets becomes more and more difficult as the disease progresses and insulin secretion inexorably fails [38], leading to a higher risk of hypoglycaemic episodes [39].

Thus, treatment-resistant diabetes encompasses multiple mechanisms that need to be assessed before considering any intensification of pharmacological therapy in the face of a T2D patient with PPDM (Fig. 1) [36]. Numerous therapies that combine medications with different and complementary glucose-lowering actions are now available, and may help both patients and physicians overcome PPDM and treatment-resistant diabetes [9].

In conclusion, a large number of $\mathrm{T} 2 \mathrm{D}$ patients have poor glycaemic control despite oral therapy combining metformin, SU and another glucose-lowering agent. Such patients may be defined as treatment-resistant and should be proposed alternative pharmacological strategies. Better knowledge of the possible causes of treatment-resistant diabetes should help in the search for appropriate solutions to overcome inherent difficulties [14]. Nevertheless, before intensifying any pharmacotherapy in

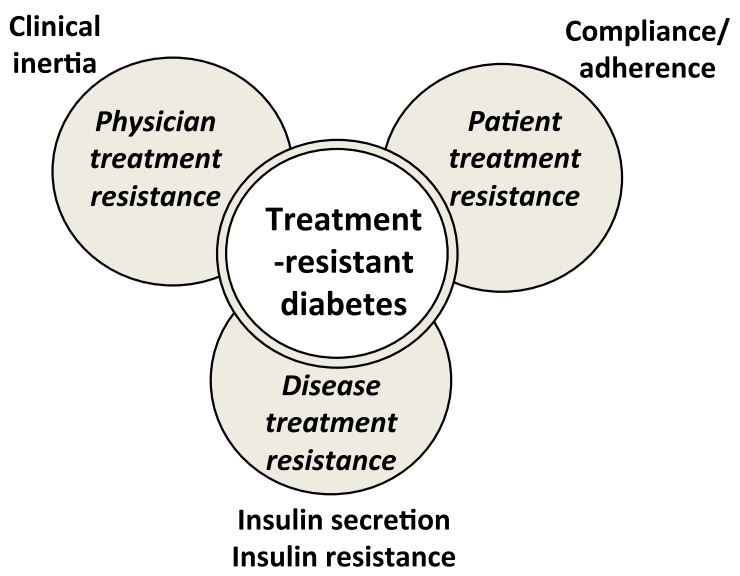

Fig. 1. Schematic illustration of the three major components comprising 'treatmentresistant diabetes'.

treatment-resistant T2D patients [9], physicians should first consider evaluating patient compliance/adherence and discuss patient preferences in a shared care approach.

\section{Funding}

No sources of funding were used to assist in the preparation of this manuscript.

\section{Disclosure of interest}

The author declares that he has no competing interest.

A.J. Scheen has received lecture/advisor fees from AstraZeneca/ BMS, Boehringer Ingelheim, Eli Lilly, Janssen, Merck Sharp \& Dohme, Novartis, Novo Nordisk and Sanofi.

\section{References}

[1] Stone MA, Charpentier G, Doggen K, Kuss O, Lindblad U, Kellner C, et al. Quality of care of people with type 2 diabetes in eight European countries: findings from the Guideline Adherence to Enhance Care (GUIDANCE) study. Diabetes Care 2013;36:2628-38.

[2] Reaven GM. Banting lecture 1988. Role of insulin resistance in human disease. Diabetes 1988;37:1595-607.

[3] DeFronzo RA, Ferrannini E. Insulin resistance. A multifaceted syndrome responsible for NIDDM, obesity, hypertension, dyslipidemia, and atherosclerotic cardiovascular disease. Diabetes Care 1991;14:173-94.

[4] Oliveras A, de la Sierra A. Resistant hypertension: patient characteristics, risk factors, co-morbidities and outcomes. J Hum Hypertens 2014;28:213-7.

[5] White WB, Turner JR, Sica DA, Bisognano JD, Calhoun DA, Townsend RR, et al Detection, evaluation, and treatment of severe and resistant hypertension: proceedings from an American Society of Hypertension Interactive forum held in Bethesda. J Am Soc Hypertens 2014;8:743-57.

[6] Muxfeldt ES, de Souza F, Salles GF. Resistant hypertension: a practical clinical approach. J Hum Hypertens 2013;27:657-62.

[7] Bangalore S, Davis BR, Cushman WC, Pressel SL, Muntner PM, Calhoun DA, et al. Treatment-resistant hypertension and outcomes based on randomized treatment group in ALLHAT. Am J Med 2017;130:439-89.

[8] Ferrannini E, Cushman WC. Diabetes and hypertension: the bad companions Lancet 2012;380:601-10.

[9] Scheen AJ. Pharmacotherapy of "treatment resistant" type 2 diabetes. Expert Opin Pharmacother 2017;18:503-15.

[10] American Diabetes Association. Standards of medical care in diabetes. Diabetes Care 2017;40:S1-35.

[11] Inzucchi SE, Bergenstal RM, Buse JB, Diamant M, Ferrannini E, Nauck M, et al. Management of hyperglycaemia in type 2 diabetes, 2015: a patient-centred approach. Update to a position statement of the American Diabetes Association and the European Association for the Study of Diabetes. Diabetologia 2015;58:429-42.

[12] Garber AJ, Abrahamson MJ, Barzilay JI, Blonde L, Bloomgarden ZT, Bush MA et al. Consensus statement by the American Association of Clinical Endocrinologists and American College of Endocrinology on the comprehensive type 2 diabetes management algorithm-2016 executive summary. Endocr Pract $2016 ; 22: 84-113$. 
[13] Bejan-Angoulvant T, Cornu C, Archambault P, Tudrej B, Audier P, Brabant Y, et al. Is HbA1c a valid surrogate for macrovascular and microvascular complications in type 2 diabetes? Diabetes Metab 2015;41:195-201.

[14] Crowley MJ, Holleman R, Klamerus ML, Bosworth HB, Edelman D, Heisler M. Factors associated with persistent poorly controlled diabetes mellitus: clues to improving management in patients with resistant poor control. Chronic Illn 2014;10:291-302.

[15] Yin J, Yeung R, Luk A, Tutino G, Zhang Y, Kong A, et al. Gender, diabetes education, and psychosocial factors are associated with persistent poor glycemic control in patients with type 2 diabetes in the Joint Asia Diabetes Evaluation (JADE) program. J Diabetes 2016;8:109-19.

[16] Aronson R, Orzech N, Ye C, Goldenberg R, Brown V. Specialist-led diabetes registries and predictors of poor glycemic control in type 2 diabetes: Insights into the functionally refractory patient from the LMC Diabetes Registry database. J Diabetes 2016;8:76-85.

[17] Khan H, Lasker SS, Chowdhury TA. Exploring reasons for very poor glycaemic control in patients with Type 2 diabetes. Prim Care Diabetes 2011;5:251-5.

[18] Abdelmoneim AS, Eurich DT, Light PE, Senior PA, Seubert JM, Makowsky MJ, et al. Cardiovascular safety of sulphonylureas: over 40 years of continuous controversy without an answer. Diabetes Obes Metab 2015;17:523-32.

[19] International Diabetes Federation (IDF). Clinical Guidelines Task Force. Global guideline for type 2 diabetes; 2012, https://www.idf.org/sites/default/files/ IDF-Guideline-for-Type-2-Diabetes.pdf [Accessed April 5, 2017].

[20] National Institute for Health and Care Excellence (NICE). Type 2 diabetes in adults: management; 2016, http://www.nice.org.uk/guidance/ng28 [Accessed April 5, 2017].

[21] Haute Autorité de Santé (HAS). Stratégie médicamenteuse du contrôle glycémique du diabète de type 2 : recommandations; 2013 , https://www.has-sante. $\mathrm{fr} /$ portail/upload/docs/application/pdf/2013-02/ 10irp04_reco diabete type 2.pdf [Accessed April 5, 2017].

[22] Palmer SC, Mavridis D, Nicolucci A, Johnson DW, Tonelli M, Craig JC, et al. Comparison of clinical outcomes and adverse events associated with glucoselowering drugs in patients with type 2 diabetes: a meta-analysis. JAMA 2016:316:313-24.

[23] McIntosh B, Cameron C, Singh SR, Yu C, Dolovich L, Houlden R. Choice of therapy in patients with type 2 diabetes inadequately controlled with metformin and a sulphonylurea: a systematic review and mixed-treatment comparison meta-analysis. Open Med 2012;6:e62-74.

[24] Zhong X, Zhang T, Liu Y, Wei X, Zhang X, Qin Y, et al. Effects of three injectable antidiabetic agents on glycaemic control, weight change and drop-out in type 2 diabetes suboptimally controlled with metformin and/or a sulfonylurea: A network meta-analysis. Diabetes Res Clin Pract 2015;109:451-60.

[25] Polonsky WH, Fisher L, Guzman S, Villa-Caballero L, Edelman SV. Psychological insulin resistance in patients with type 2 diabetes: the scope of the problem. Diabetes Care 2005;28:2543-5.

[26] Ross SA, Tildesley HD, Ashkenas J. Barriers to effective insulin treatment: the persistence of poor glycemic control in type 2 diabetes. Curr Med Res Opin 2011;27(3):13-20.

[27] Petrak F, Stridde E, Leverkus F, Crispin AA, Forst T, Pfutzner A. Development and validation of a new measure to evaluate psychological resistance to insulin treatment. Diabetes Care 2007;30:2199-204.

[28] Wang HF, Yeh MC. Psychological resistance to insulin therapy in adults with type 2 diabetes: mixed-method systematic review. J Adv Nurs 2012;68:74357.
[29] Cramer JA. A systematic review of adherence with medications for diabetes. Diabetes Care 2004:27:1218-24.

[30] Bailey CJ, Kodack M. Patient adherence to medication requirements for therapy of type 2 diabetes. Int J Clin Pract 2011;65:314-22.

[31] Grimaldi A, Penfornis A. Consoli S, Falissard B, Eymard E, Williams P, et al Breaking barriers to effective type 2 diabetes management: findings from the use of the OPTIMA(c) questionnaire in clinical practice. Adv Ther 2016;33:1033-48.

[32] Reach G, Pechtner V, Gentilella R, Corcos A, Ceriello A. Clinical inertia and its impact on treatment intensification in people with type 2 diabetes mellitus. Diabetes Metab 2017;43.

[33] Grant R, Adams AS, Trinacty CM, Zhang F, Kleinman K, Soumerai SB, et al Relationship between patient medication adherence and subsequent clinical inertia in type 2 diabetes glycemic management. Diabetes Care 2007;30:80712.

[34] Reach G. Patient non-adherence and healthcare-provider inertia are clinical myopia. Diabetes Metab 2008;34:382-5.

[35] Khunti K, Wolden ML, Thorsted BL, Andersen M, Davies MJ. Clinical inertia in people with type 2 diabetes: a retrospective cohort study of more than 80,000 people. Diabetes Care 2013;36:3411-7.

[36] Halimi S, Balkau B, Attali C, Detournay B, Amelineau E, Blickle JF. Therapeutic management of orally treated type 2 diabetic patients, by French general practitioners in 2010: the DIAttitude Study. Diabetes Metab 2012;38(Suppl 3):S36-46.

[37] Kunt T, Snoek FJ. Barriers to insulin initiation and intensification and how to overcome them. Int J Clin Pract Suppl 2009;164:6-10.

[38] de Pablos-Velasco P, Parhofer KG, Bradley C, Eschwege E, Gonder-Frederick L, Maheux P, et al. Current level of glycaemic control and its associated factors in patients with type 2 diabetes across Europe: data from the PANORAMA study. Clin Endocrinol (Oxf) 2014:80:47-56.

[39] Simon D, de Pablos-Velasco P, Parhofer KG, Gonder-Frederick L, Duprat Lomon $\mathrm{I}$, Vandenberghe $\mathrm{H}$, et al. Hypoglycaemic episodes in patients with type 2 diabetes-risk factors and associations with patient-reported outcomes: The PANORAMA Study. Diabetes Metab 2015;41:470-9.

A.J. Scheen ${ }^{\mathrm{a}, \mathrm{b}, *}$

${ }^{a}$ Clinical Pharmacology Unit, CHU Liège, Center for Interdisciplinary Research on Medicines (CIRM), University of Liège, avenue de l'Hôpital,1, 4000 Liège, Belgium

${ }^{\mathrm{b}}$ Division of Diabetes, Nutrition and Metabolic Disorders, Department of Medicine, CHU Liège, 1, avenue de l'Hôpital, 4000 Liège, Belgium

${ }^{*}$ Correspondence. Department of Medicine, CHU Sart-Tilman (B35), 4000 Liege 1, Belgium

E-mail address: andre.scheen@chu.ulg.ac.be

Received 10 April 2017

Accepted 18 April 2017

Available online 25 May 2017 